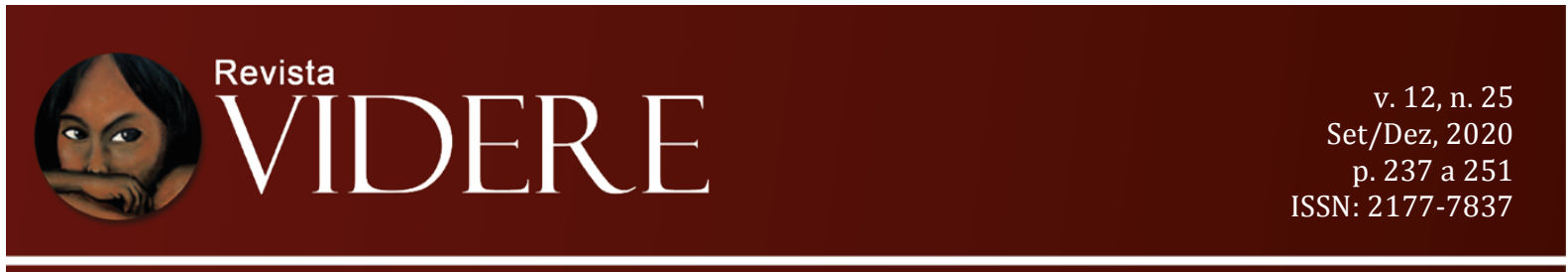

\title{
ANÁLISE CRÍTICA DOS REQUISITOS MÍNIMOS PARA LOTES URBANOS E POSSIBILIDADES DE FLEXIBILIZAÇÃO NO ÂMBITO DA REGULARIZAÇÃO FUNDIÁRIA
}

\author{
CRITICAL ANALYSIS OF THE MINIMUM REQUIREMENTS FOR URBAN LAND \\ PLOTS AND THE POSSIBILITIES OF FLEXIBILIZATION WITHIN THE SCOPE OF \\ LAND REGULARIZATION
}
ANÁLISIS CRÍTICO DE LOS REQUISITOS MÍNIMOS DE LOTES URBANOS Y POSIBILIDADES DE FLEXIBILIZACIÓN EN EL ÁMBITO DE LA REGULARIZACIÓN DEL SUELO

\begin{abstract}
Rogério Gesta Leal Doutor em Direito, Professor da Universidade de Santa Cruz do Sul Desembargador do Tribunal de Justiça do RS rleal@unisc.br Orcid: orcid.org/0000-0002-2005-241X.
\end{abstract}

\begin{abstract}
Guilherme Augusto Faccenda Mestre em Direito pela Fundação Escola Superior do Ministério Público do RS. Tabelião de Notas no Estado do Rio Grande do Sul. guilhermefaccenda@gmail.com Orcid: orcid.org/0000-0003-2200-5622.
\end{abstract}

Resumo: O presente artigo busca analisar a situação jurídica dos requisitos urbanísticos para regularidade de um lote de terreno urbano, considerando as condições mínimas para que se repute digna uma moradia, e como forma de pautar as políticas públicas de regularização fundiária. Nesta senda, questiona-se como deverá se concretizar a flexibilização dos referidos requisitos, o que foi previsto em lei para fins de facilitar a legalização imobiliária, sem comprometimento do bem-estar dos habitantes. Através do método hermenêutico dialético, objetiva-se esclarecer, sem pretensão de esgotamento do tema, o alcance das previsões empregadas na legislação em comparação com os ditames da moradia. Este breve espaço de pesquisa conclui pela impossibilidade do elenco a priori de dispensa de melhoramentos urbanos, cabendo aos entes de fiscalização urbana a instrumentalização de técnicas para a correta apuração, em cada caso social, das necessidades da área urbana que se regulariza.

Palavras-Chave: Lote urbano. Direito de Moradia. Regularização Fundiária.

Abstract: The present article seeks to analyze the legal situation of urban requirements for the regularity of a plot of urban land, considering the minimum conditions for a house to be considered worthy, and as a way of guiding public land regularization policies. In this way, it 
is questioned how the flexibilization of these requirements should take place, which was provided by law for the purpose of facilitating real estate legalization, without compromising the well-being of the inhabitants. Through the dialectical hermeneutic method, the objective is to clarify, without the intent of exhausting the topic, the scope of the forecasts used in the legislation in comparison with the dictates of housing. This brief research space concludes that the a priori list of urban improvements is not possible, leaving the urban inspection entities to instrumentalize techniques for the correct determination, in each social case, of the needs of the urban area that is being regularized.

Keywords: Urban plot. Housing Law. land tenure regularization.

Resumen: Este artículo busca analizar la situación jurídica de los requisitos urbanísticos de regularidad de una parcela de suelo urbano, considerando las condiciones mínimas para la reputación de una vivienda digna, y como una forma de orientar las políticas de regularización del suelo público. De esta manera, se cuestiona cómo debe materializarse la flexibilización de estos requisitos, que fue prevista por ley con el propósito de facilitar la legalización inmobiliaria, sin comprometer el bienestar de los habitantes. A través del método hermenéutico dialéctico, el objetivo es aclarar, sin pretender agotar el tema, el alcance de las previsiones utilizadas en la legislación en comparación con los dictados de la vivienda. Este breve espacio de investigación concluye que es imposible que la lista a priori prescinda de mejoras urbanísticas, y corresponde a las entidades de inspección urbanística instrumentalizar técnicas para la correcta determinación, en cada caso social, de las necesidades del área urbana que se está regularizando.

Palabras clave: Parcela urbana. Ley de Vivienda. Regularización de suelo.

\section{Considerações introdutórias}

O direito fundamental, de caráter social, à moradia foi adicionado ao artigo $6^{\circ}$ da Constituição Federal através da Emenda Constitucional número 26 no ano de 2000, embora já fosse reconhecido como direito humano desde 1948 (artigo 25 da Declaração Universal dos Direitos Humanos). Para José Afonso da Silva, é possível considerar o direito à moradia como previsão originária do Constituinte de 1988, pois, ao artigo 23 da Magna Carta, fixou-se ser competência comum dos entes federados a promoção de programas de construção de moradias e a melhoria das condições habitacionais e de saneamento (SILVA, 2013, p. 318). Seguindo a linha da complexidade da moradia, defende o constitucionalista que a moradia deve garantir uma série de outros direitos (como dignidade, saúde e intimidade) sob pena de ser um "direito empobrecido" (SILVA, 2013, p. 318). Este importante direito humano e fundamental não deve ser pensado como uma perspectiva isolada, passível de cumprimento por um único ato ou obra do Poder Público, mas sim dotado de carga prospectiva para progressivo cumprimento e melhoria urbana geral, lido em conjunto com o artigo 182 da Constituição. 
O solo urbano é mais trabalhado que o rural pela presença de equipamentos urbanos e comunitários que servem à população - e o conhecido problema do parcelamento desordenado do solo vem consubstanciado principalmente na ausência destes equipamentos, o que diminui gravemente a qualidade de vida da população afetada. Para José Afonso da Silva:

\begin{abstract}
A qualificação do solo como urbano e função dos planos e normas urbanísticos, que lhe fixam o destino urbanístico a que fica vinculado o proprietário. O solo passa a ter qualificação urbana quando ordenado para cumprir destino urbanístico, especialmente a edificabilidade e a vialidade (de viário) — que não são, por natureza, qualidades do solo. Essa qualificação e função das normas urbanísticas que lhe fixam o destino urbanístico, a que fica vinculado o proprietário. Esse destino consiste primordialmente na ordenação do terreno e na sua predeterminação a uma das funções do urbanismo (SILVA, 2010, p. 80).
\end{abstract}

Quem primeiro explicou a imprescindibilidade de múltiplos fatores de adequação do solo urbano para que efetivamente se torne o hábitat humano que se busca foi o sociólogo e filósofo francês Henri Lefebvre, precursor do chamado direito à cidade - hoje positivado ao artigo $2^{\circ}$ do Estatuto da Cidade. O referido autor observa que até os revolucionários esqueceram do elemento urbano, enquanto os "táticos políticos" só enxergam e prometem a moradia como solução para o adoecido, dividido e desigual espaço urbano (LEFEBVRE, 2011. p. 80/81). O problema das cidades vai muito além do aspecto "moradia" LEFEBVRE, 2011. p. 86) e sua solução necessita muito mais que apenas o fornecimento de casas - o que foi tentado na década de 60 , no Brasil, através do sistema de financeirização proposta pela Lei 4.380, instituidora do Sistema Financeiro de Habitação. De qualquer forma, a ótica mais adequada para a busca de um direito à moradia completo e adequado se dará na perspectiva do direito à cidade. O legislador pátrio, já de início, consagrou tal conteúdo múltiplo ao direito à cidade. In verbis:

Art. $2^{\circ}$ A política urbana tem por objetivo ordenar o pleno desenvolvimento das funções sociais da cidade e da propriedade urbana, mediante as seguintes diretrizes gerais:

I - garantia do direito a cidades sustentáveis, entendido como o direito à terra urbana, à moradia, ao saneamento ambiental, à infra-estrutura urbana, ao transporte e aos serviços públicos, ao trabalho e ao lazer, para as presentes e futuras gerações;

Desta forma, mesmo que se adote, para o âmbito interno brasileiro, uma interpretação extremamente conservadora e restritiva (o que se diz ad argumentandum tantum, já que direitos humanos não comportam interpretações restritivas de sua eficácia), o positivismo dogmático, por assim dizer, do Estatuto da Cidade já insere, por si, a sustentabilidade, o direito à terra urbana, ao saneamento, à infraestrutura urbana, à moradia, 
ao transporte, ao lazer, ao trabalho, aos serviços públicos e submete todos estes ao princípio do pacto intergeracional - ou seja, sua realização deve obrigatoriamente ocorrer a longo prazo, sem o esgotamento de recursos ou adoção de políticas prestativas tendentes a impedir a continuidade de tais prestações. Portanto, a interpretação mais conservadora possível abarcaria dez direitos (sem considerar que o caput do artigo ainda inclui as funções sociais da cidade e da propriedade sob o manto protetivo) contidos no plexo do direito à cidade

$\mathrm{O}$ direito à cidade empresta sua multiplicidade e sua complexidade ao imóvel urbano e àquilo que dele legitimamente se espera. Para que se cumpra a contento este direito fundamental essencial à qualidade de vida, uma moradia deve oferecer suficientes benefícios ao morador e, como direta consequência, incrementa o investimento e o planejamento de sua produção e manutenção, tanto para o público quanto para o privado. Em cenários irregulares, além de defeitos documentais de titularidade, as políticas públicas de regularização fundiária deverão levar em consideração quais aspectos materiais devem ser implementados para a efetivação dos direitos fundamentais urbanos.

Dentro deste cenário, e para o aumento das possibilidades de regularização fundiária, os instrumentos legislativos têm estabelecido a possibilidade de se flexibilizar os requisitos urbanísticos dos lotes. O artigo 11 da Lei 13.465, primeiro parágrafo, estabelece que "para fins da Reurb, os Municípios poderão dispensar as exigências relativas ao percentual e às dimensões de áreas destinadas ao uso público ou ao tamanho dos lotes regularizados, assim como a outros parâmetros urbanísticos e edilícios", com redação aberta e sem especificar quais parâmetros são passíveis de dispensa, surgindo o problema prático que justifica a presente pesquisa.

A flexibilização proposta poderá surgir com traços extremamente complexos pois, mais do que apenas apresentar uma facilidade materialística, gera-se potencial relativização de direito fundamental social. Desta forma, dentro deste breve espaço de pesquisa, serão analisados, utilizando o método hermenêutico dialético, alguns dos principais requisitos que um lote urbano deve conter e como vem sendo tratados os casos de flexibilização, sem a pretensão de se esgotar o tema.

\section{Requisitos urbanísticos dos lotes}

A ideia por trás do conceito de solo urbano remonta ao direito romano, onde a "urbs" era a cidade, em oposição à área rural "rus" (CARVALHO FILHO, 2013. p. 02), esta dedicada a atividades próprias de produção rural, enquanto aquela abarcava a vida humana em 
seus múltiplos aspectos e desenvolvimentos - apesar da dependência recíproca de ambas. A primeira legislação relativa a loteamentos no Brasil foi o Decreto-Lei 58 de 1937, que se dedicava quase exclusivamente a proteger os adquirentes de lotes de imóveis, pois, até então, dependiam somente da boa-fé dos vendedores. A regularidade contratual e dominial não é menos importante pois, sem ela, os compradores jamais teriam segurança na aquisição imobiliária, a qual pode representar importante negócio jurídico na vida de uma família que busca moradia. Defende, aliás, o economista Hernando de Soto que o caminho para o sucesso econômico do capitalismo em países periféricos é justamente a titulação das posses e propriedades, formalizando a economia e permitindo o uso e a circulação da riqueza (SOTO, 2000).

No entanto, como se disse, não é qualquer moradia que deve ser buscada pelo Direito, mas sim uma moradia digna e integrada à cidade. Foi a Lei de Parcelamento do Solo Urbano, número 6.766 do ano 1979, conhecida como Lei Lehmann (em homenagem ao falecido senador Otto Cyrillo Lehmann) que teve cuidado com os requisitos urbanísticos do solo, e definiu equipamentos urbanos e equipamentos comunitários como parte da infraestrutura esperada em solo urbano:

\footnotetext{
Art. $2^{\circ}[\ldots]$

$\S 5^{\circ} \mathrm{A}$ infra-estrutura básica dos parcelamentos é constituída pelos equipamentos urbanos de escoamento das águas pluviais, iluminação pública, esgotamento sanitário, abastecimento de água potável, energia elétrica pública e domiciliar e vias de circulação.

$[\ldots]$

Art. $4^{\circ}[\ldots]$

$\S 2^{\circ}$ - Consideram-se comunitários os equipamentos públicos de educação, cultura, saúde, lazer e similares.
}

Como tamanho mínimo de lote, estabeleceu o padrão nacional de $125 \mathrm{~m}^{2}$, com 5 metros de frente, sendo que as legislações urbanas locais poderão estabelecer medidas maiores. Interessante notar que, como forma de estimular a Administração Pública dos Municípios brasileiros a efetivamente cumprirem os padrões urbanos mínimos, o Código Tributário Nacional, ao artigo 32, fixou que a tributação por IPTU fica condicionada à efetiva existência de melhoramentos urbanos.

Art. 32. (...).

$\S 1^{\circ}$ Para os efeitos deste imposto, entende-se como zona urbana a definida em lei municipal; observado o requisito mínimo da existência de melhoramentos indicados em pelo menos 2 (dois) dos incisos seguintes, construídos ou mantidos pelo Poder Público:

I - meio-fio ou calçamento, com canalização de águas pluviais; 


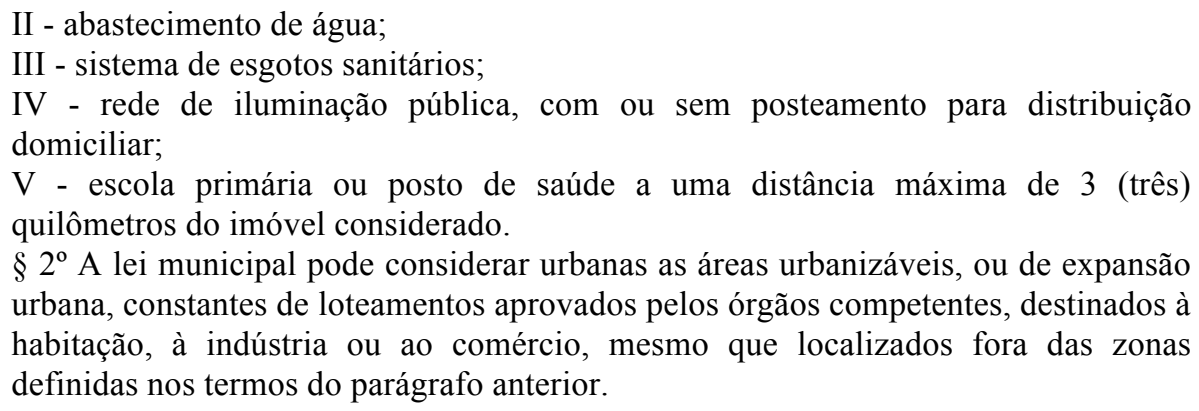

Sobre a aplicação prática do referido artigo, elenca-se o disposto na Súmula número 626 do Superior Tribunal de Justiça, segundo a qual "A incidência do IPTU sobre imóvel situado em área considerada pela lei local como urbanizável ou de expansão urbana não está condicionada à existência dos melhoramentos elencados no art. $32, \S 1^{\circ}$, do CTN". Dos variados precedentes que deram origem à súmula em comento, destaca-se o argumento presente no Recurso Especial número 1.655.031/SP segundo o qual será responsabilidade do loteador, nestes casos, a implantação dos melhoramentos urbanos referidos, cabendo ao Município apenas fiscalizar o andamento das obras conforme cronograma. O problema desta situação, como se verá adiante, é o pressuposto de que o loteador cumpriu as normas da Lei 6.766, levando a Registro público o projeto de urbanização aprovado e acompanhado de cronograma das obras - o que muitas vezes não ocorre.

Internacionalmente, tendo em vista o caráter de direito humano que o direito à moradia possui, foi emitido em 1991 pelo Comitê de direitos Econômicos, Sociais e Culturais da ONU o comentário geral número $4^{1}$, destinado a especificar padrões mínimos para a moradia. O comentário elenca sete aspectos considerados necessários para a adequação do direito à moradia: o primeiro é a segurança da posse ou da propriedade, devendo o país signatário possuir elementos de segurança mesmo nos casos de locação de imóvel; o segundo é a disponibilidade de serviços materiais, tá marcando nutrição, saúde, e segurança; o terceiro é a acessibilidade de custos de construção, também possíveis de se obter através de programas de subsídios; o quarto é a habitabilidade, de forma a proteger os moradores contra os elementos e perigos da natureza, incluindo calor e chuva; o quinto é a acessibilidade voltada a idosos, crianças, e deficientes; a localização, que deve ser projetada para permitir acesso a serviços de saúde, segurança e educação, incluindo áreas rurais; e, por último, a adequação cultural, de modo a abarcar as mais modernas técnicas de construção civil.

Um dos grandes desafios da elaboração de instrumentos internacionais justamente reside em criar consenso entre povos de idiomas e culturas extremamente diversas, as quais 
abarcarão diferentes necessidades e preferências. Cite-se como exemplo a preocupação da Agenda Habitat III em criar "cidades inteligentes", as chamadas "smart cities", em cujas infraestruturas pretende-se a inserção de tecnologias tais que fiquem resolvidos problemas de energias, ambientais, transportes e afins. Henri Lefebvre, idealizador do direito à cidade, criticou o "cientificismo" e as tecnologias por enxergar nestas uma fonte de "novas necessidades" e, pois, de "novas pobrezas" (LEFEBVRE, 2011, p. 124/125), entretanto, a visão mais contemporânea e internacional enxerga a salvação de muitos direitos básicos por meio de avanços tecnológicos. Através de novas técnicas será possível baratear o acesso à saúde, a energias, meios de transporte e mesmo à construção de moradias ${ }^{2}$. A citada plataforma do conselho de cidades inteligentes, reconhecendo a pesada desigualdade urbana no planeta, justamente propõe que somente a "inovação gera a inclusão"3.

O que se percebe, destarte, é a visão ampla necessária para se revelar o conteúdo real que o direito fundamental social à moradia busca, não se limitando a uma construção imobiliária. A par da residência em si, serão necessários serviços de fornecimento de água, eletricidade, esgotamento, vias de acesso integradas, escoamento de águas pluviais, e inserção na rede de serviços de saúde, educação, segurança, dentre outros. $\mathrm{O}$ atendimento do padrão internacional requer, ainda, segurança de domínio, observância de padrões culturais, proteção contra elementos naturais de risco, acessibilidade e moderação de custos. Um outro possível diálogo de fontes e dá em relação a chamada teoria do patrimônio mínimo, que surge como garantia de mínimo existencial, ou seja, é plausível cogitar um direito fundamental a moradia que procure sempre acompanhar as melhorias tecnológicas e sociais. Por esse motivo, o padrão internacional preocupou-se com a segurança que a moradia é capaz de propiciar contra elementos naturais e externos, trazendo consigo a busca pelos padrões de construção segundo a técnica mais recente.

Em relação aos números representativos do cenário brasileiro, o relatório ${ }^{4}$ do IPEA apresentado na conferência Habitat III da ONU em 2016 atesta que, em 2013, 84,4\% da população brasileira residia em cidades (número rapidamente crescente), 16,68\% dos jovens (entre 19 e 29 anos) sem trabalho ou estudo, apenas 19\% dos Municípios contando com políticas de acessibilidade, $47 \%$ dos Municípios com planos diretores, apesar de $91 \%$ ter algum tipo de legislação urbana (mas apenas 18,8\% com órgão urbano específico de

${ }^{2}$ Cita-se como exemplo a impressora 3D que constrói uma casa em 24 horas: http://gq.globo.com/Prazeres/Design/noticia/2017/03/casa-e-feita-com-impressora-3d-em-24-horas-por-r-32mil.html. Acesso em fevereiro de 2020.

${ }^{3}$ Disponível em http://smartcitiescouncil.com/. Acesso em Acesso em fevereiro de 2020.

${ }^{4}$ Disponível em http://habitat3.org/wp-content/uploads/National-Report-LAC-Brazil-Portuguese.pdf. Acesso em 04 de fevereiro de 2020. 
habitação). Um dado de importância particular do ponto de vista de política habitacional é que $40,11 \%$ dos domicílios foram classificados como inadequados em 2013, apesar de 99,94\% terem acesso a energia elétrica e 97\% acesso à água - enquanto o esgoto sanitário chegou a $82,52 \%$.

Dentro desta circunstância de população predominantemente urbana, os índices de acesso à água e à eletricidade são positivos (acima de 90\%), cumprindo em grande parte relevantes aspectos do direito à moradia. Já os índices de acesso à educação, emprego e esgotamento sanitário necessitam de melhorias no sentido de atingir toda a população. Porém, a respeito da titulação, quase $60 \%$ dos imóveis ${ }^{5}$ domiciliares no Brasil não possuem título de propriedade, em grande parte por conta de loteamentos clandestinos (constando notícias de cidades inteiras em situações de irregularidade).

Outra fonte de problema, dependente de diálogo com a seara jurídica penal, foi a opção legislativa pela pura e simples criminalização da promoção de parcelamentos do solo em desacordo com a legislação. A lei penal deve ser clara, certa, estrita e necessária, todavia, o artigo 50 da Lei 6.766 , de outro lado, chega ao ponto de tornar crime contra a Administração Pública a promoção de parcelamento em "desacordo com a lei ou com normas pertinentes dos Estados, Municípios ou Distrito Federal”.

A criminalização excessivamente aberta de condutas ligadas a irregularidades em parcelamentos de solo, aliada a uma falta geral de titulação de imóveis, danifica não apenas o direito à moradia como também a própria economia nacional. Hernando de Soto (2000, p. 20) explica, em detalhado estudo sobre economias de países periféricos, que certos modelos estatais dificultam ou obstam a obtenção de uma situação de legalidade, ainda que este status seja desejado pelas pessoas.

Além da necessidade de reformulação da tipificação penal, é extremamente adequada a busca de um caminho flexibilizador principiológico para a política pública de regularização fundiária. A lei do parcelamento do solo peca gravemente ao não discriminar adequadamente quais condutas devem ser tipificadas como crime - para daí elencá-las em gravidade em penas proporcionais. Consequentemente, por não equacionar justamente situações de regularidade (as quais, como se viu, poderão ser das mais diversas possíveis, desde um mero descumprimento de formalidade até a promoção de um loteamento inteiramente clandestino), cria-se insegurança ao loteador que tenta cumprir a lei e estímulo àquele loteador que nunca pretendeu cumprir a lei. 
Eis a gênese do principal desafio interpretativo do artigo 11 da Lei 13.465: as irregularidades fundiárias são capazes de tomar as mais variadas formas e afetar um, ou mais, dos diversos aspectos da moradia adequada, sendo inviável uma solução legal apriorística. E, como fator agravante, cada vez que se flexibiliza um requisito urbanístico do lote queria ser uma relativização de um direito fundamental. Uma flexibilização ampla e restrita fulminaria o direito fundamental a moradia, ao passo em que a impossibilidade de flexibilização poderia inviabilizar a regularização fundiária e a titulação de uma ocupação já consolidada no tempo e integrada à cidade.

\section{Condições e possibilidades de flexibilização}

Se o direito à cidade, ou o direito à moradia, conecta-se a amplos e extensos aspectos e consequências sociais, é certo que a regularização fundiária promovida sobre determinado imóvel terá consequências positivas reverberadas para todos estes demais direitos. Torna-se uma ferramenta eficaz à disposição do bom administrador público para cobrir uma vasta gama de direitos fundamentais conexos dentro de um mesmo procedimento, e com consequências positivas a longo prazo. Dito de outra forma, a obtenção de moradia regular e adequada auxiliará na concretização de outros direitos fundamentais conexos, tais como saúde, segurança, educação e transporte.

Como norte interpretativo, o próprio legislador forneceu três exemplos de possíveis flexibilizações de requisitos urbanísticos para o lote, mencionando o percentual e as dimensões de áreas públicas, e o tamanho dos lotes. Repare que as medidas dos lotes, por óbvio dentro de parâmetros de razoabilidade para abrigar vida humana, poderão ter impactos na ordem urbanística e nas transações comerciais imobiliárias, mas não impedindo o fornecimento de serviços de subsistência, como água e eletricidade, ou acesso a serviços de educação e saúde. Ou seja, opera-se um sacrifício de padrões de engenharia, embelezamento e ordenação urbanísticos com a finalidade maior desse trazer para a legalidade os ocupantes de um loteamento irregular, havendo a escolha de direitos de necessidade constitucional imediata.

De outra banda, a leitura constitucional da possibilidade de flexibilização de requisitos urbanos permite inferir a impossibilidade do abrandamento da presença de equipamentos urbanos umbilicalmente ligados à subsistência humana digna, como serão os casos de fornecimento de água, luz, tratamento sanitário escoamento pluviométrico. Os aspectos referentes a subsistência e a dignidade humana não poderão ser superados para que 
se atinja a regularização ou titulação imobiliária, pois tal situação jamais estaria regularizada sob ponto de vista dos direitos fundamentais. O solo urbano desprovido de melhoramentos seria um paradoxo, pois são justamente estes fatores que emprestam ao solo a característica de urbano.

Um requisito que, embora importante, também poderia ser abrandado será a iluminação pública, pois o próprio legislador já abriu esta possibilidade ao tratar das ZHIS (zonas habitacionais de interesse social) no artigo $2^{\circ}$, parágrafo $6^{\circ}$ da Lei de Parcelamento. No caso, permanecem obrigatórias o fornecimento de água, eletricidade, esgoto, escoamento pluviométrico e vias de circulação, adaptando-se à lógica aqui exposta de preservar aquilo que diz respeito à subsistência humana digna.

Em relação à mensuração imobiliária, a constitucionalidade de sua possibilidade de flexibilização encontra-se no artigo 183 da Constituição Federal, que positiva a usucapião especial Urbana individual como direito fundamental. Inicialmente, o texto original da Lei 11.977 de 2009 vedava a concessão de legitimação de posse em lotes de mais de $250 \mathrm{~m}^{2}$. O norte interpretativo do legislador seria criar um paralelo entre a regularização fundiária e a usucapião urbana constitucional. Buscava-se, pois, atrelar os institutos garantidores de moradia e função social da propriedade.

Porém, a escolha mostrou-se problemática em cenários de ocupação desordenada, e a lei veio a ser alterada, com a supressão desta limitação, pela Lei 12.424, no ano de 2011. A determinação passou a ser no sentido de que, no caso de área urbana de mais de $250 \mathrm{~m}^{2}$, o prazo para requerimento da conversão do título de legitimação de posse em propriedade será o estabelecido na legislação pertinente sobre usucapião. Assim, restou plenamente possível que o lote extrapole essas medidas e abarque outras formas de usucapião previstas. Tal determinação melhor amolda-se ao procedimento legal e aos institutos da usucapião, pois áreas objetos de regularização fundiária se originam de ocupações urbanas por vezes absolutamente desordenadas, dificultando até mesmo sua divisão; diante disso, uma interpretação estrita bloquearia o acesso à legitimação de posse a um lote de $260 \mathrm{~m}^{2}$ (duzentos e sessenta metros quadrados).

Fica claro o elo estabelecido entre a prescrição aquisitiva e a regularização fundiária, pois o manutenção no tempo de uma situação de ocupação será o principal fundamento jurídico de titulação imobiliária. Por este motivo será imprescindível que o agente promotor da regularização analise as modalidades de usucapião previstas no ordenamento jurídico brasileiro, realizando a subsunção da norma pertinente ao caso concreto que lhe for apresentado - sendo plenamente possível que, em uma mesma área objeto de 


\section{ANÁLISE CRÍTICA DOS REQUISITOS MÍNIMOS PARA LOTES URBANOS E POSSIBILIDADES DE FLEXIBILIZAÇÃO NO ÂMBITO DA REGULARIZAÇÃO

regularização, estejam presentes as mais variadas formas de usucapião. Entretanto, aponta-se a divergência jurisprudencial originada pela questão da metragem imobiliária em relação às leis municipais territoriais:

USUCAPIÃO. IMÓVEL. ÁREA MENOR. MÓDULO MÍNIMO. Trata-se de ação de usucapião extraordinário em que se pretende usucapir imóvel com área menor do que o módulo mínimo estabelecido pela lei municipal. No caso, o imóvel pretendido tem $126 \mathrm{~m} 2$, enquanto o Plano Diretor do Município disciplina que o módulo mínimo para parcelamento de solo urbano no local é de $250 \mathrm{~m} 2$. Logo não se pode deferir a pretensão do recorrente, pois o imóvel que busca usucapir não atende as normas que estabelecem o módulo mínimo. Não se pode legalizar o que a lei não permite. Assim, a Turma não conheceu do recurso. REsp 402.792-SP, Rel. Min. Jorge Scartezzini, julgado em 26/10/2004.

No caso, um indivíduo, buscando moradia, ocupou terreno sem atentar ao tamanho da área. O STJ, entretanto, interpretou a metragem mínima urbana como verdadeiro "módulo urbano", impossibilitando a legalidade de terrenos menores no território municipal. A Lei $6.766 / 79$, em seu artigo $4^{\circ}$, estabelece requisitos mínimos para os lotes, dentre os quais uma área básica de $125 \mathrm{~m}^{2}$ (cento e vinte e cinco metros quadrados), mas permite que lei local estabeleça medida maior. No caso em comento, a metragem tomada pelo ocupante estava de perfeito acordo com a valoração métrica estabelecida pelo legislador federal - porém, para seu infortúnio, em descompasso com a valoração métrica do legislador municipal. O que foi factível para o ente federal e para o ocupante do terreno não o foi para o ente municipal - e isso apenas em termos de medidas, pois o que de fato era factível e buscado pelo morador era uma moradia, não uma metragem de área.

O Supremo Tribunal Federal, no entanto, utilizando-se de interpretação que busca a máxima efetividade dos direitos fundamentais, decidiu de maneira diversa, proferindo o seguinte julgado em 29 de abril de 2015, de relatoria do Ministro Dias Toffoli:

Recurso extraordinário. Repercussão geral. Usucapião especial urbana. Interessados que preenchem todos os requisitos exigidos pelo art. 183 da Constituição Federal. Pedido indeferido com fundamento em exigência supostamente imposta pelo plano diretor do município em que localizado o imóvel. Impossibilidade. A usucapião especial urbana tem raiz constitucional e seu implemento não pode ser obstado com fundamento em norma hierarquicamente inferior ou em interpretação que afaste a eficácia do direito constitucionalmente assegurado. Recurso provido. 1. Módulo mínimo do lote urbano municipal fixado como área de $360 \mathrm{~m} 2$. Pretensão da parte autora de usucapir porção de $225 \mathrm{~m} 2$, destacada de um todo maior, dividida em composse. 2. Não é o caso de declaração de inconstitucionalidade de norma municipal. 3. Tese aprovada: preenchidos os requisitos do art. 183 da Constituição Federal, o reconhecimento do direito à usucapião especial urbana não pode ser obstado por legislação infraconstitucional que estabeleça módulos urbanos na respectiva área em que situado o imóvel (dimensão do lote). 4. Recurso extraordinário provido. RE n 422349/RS. 
No caso em comento, interpretou-se que o direito à moradia, gerado pelo instrumento constitucional da usucapião especial urbana, não é passível de ser restringido por conta de unidades métricas que o ente municipal viu por bem adotar, ainda que com esta medida se busque maior ordenação territorial ou paisagística. Ingo Sarlet refere "aqui poderse-ia cogitar de um direito fundamental ao usucapião especial e urbano (art. 183 da CF) como manifestação dos direitos à propriedade e à moradia e, neste sentido, também como expressão e exigência da própria dignidade da pessoa humana" (SARLET, 2015. P. 64). Para Cristiano Chaves de Farias e Nelson Rosenvald, a moradia poderá ser exercida tanto em um simples barraco como em um belo palacete (FARIAS; ROSENVALD, 2014. Pg. 381), e o dispositivo apenas faz referência às dimensões do terreno, não importando a qualidade das acessões realizadas.

Apesar de a usucapião ter importância a nível constitucional e ser a base da regularização dominial da Reurb, não se deve esquecer que o instituto tem dedicação predominantemente voltada à aquisição de direito real de propriedade (ressalvado o caso da usucapião Urbana especial coletiva, no qual o estatuto das cidades apenas permite a extinção do condomínio depois da realização das obras urbanas de melhoria). A titularização formal da propriedade é um passo de extrema importância para a integração da população de baixa renda no mercado formal de patrimônio e de crédito, possibilitando toda a sorte de atos jurídicos que irão desde a compra e venda até a transmissão por herança ou doação. Entretanto, o estado e o agente parcelador do solo não serão desonerados de suas obrigações de melhorias na moradia.

Por fim, em relação aos percentuais e tamanhos das áreas públicas do parcelamento, a mesma lógica que exposta deverá ser aplicada por analogia. A existência de serviços públicos essenciais para a dignidade humana não poderá ser dispensada ou ter sua eficiência diminuída em prol da titulação mobiliária. Entretanto, demais bens públicos de uso comum, como praças e parques, poderão ter seus tamanhos mudados e adequados para cada caso específico de reordenação da urbanização.

\section{CONSIDERAÇÕES FINAIS}

Portanto, resta estabelecida a premissa de que a moradia é um direito fundamental conexo a diversos outros relativos à convivência e ao desenvolvimento da personalidade humana, sendo mais adequado contextualizá-la e unificá-la na figura em construção do direito fundamental à cidade, que melhor explica o âmbito urbano como habitat humano por 
excelência. Os diversos aspectos contidos no direito fundamental à moradia serão expressos nas qualificações e melhoramentos do solo urbano, que são elementos da essência deste urbano.

Porém, existe a possibilidade de se flexibilizar requisitos urbanísticos em um procedimento de regularização fundiária, para que se transportem à legalidade aqueles habitantes de moradias que, por uma série de motivos, estão em situação irregular. A nova lei de regularização fundiária foi propositalmente imprecisa, deixando de elencar quais elementos característicos do solo urbano poderiam ser abrandados a fim de se considerar o imóvel regularizado. O que se busca é a legalização do parcelamento urbano sem que com isso se fulmine o direito à moradia digna em seus multifacetados aspectos.

A maneira mais adequada para que se opere esta flexibilização será a partir da ordem constitucional e deverá ter como epicentro axiológico os direitos fundamentais, em especial aqueles voltados para necessidades básicas de subsistência do ocupante e de sua família. Não é desejável a promoção meramente formal da regularidade urbana, sendo os principais agentes fiscalizadores dessa situação o Ministério Público, enquanto agente protetor da ordem urbanística, e o Município, principal responsável pela ordenação do próprio território. Será preciso efetivo mapeamento e estudo social no local a ser regularizado para que se identifiquem precisamente as deficiências urbanísticas que afetam o parcelamento irregular, bem como a busca identificação dos responsáveis pela promoção das irregularidades, os quais deverão ressarcir os cofres públicos dos valores despendidos.

Não se pode defender uma flexibilização prévia do procedimento de parcelamento do solo urbano, sob pena de se fomentar a ilegalidade e gerar construção de moradias propositalmente inadequadas, com o fito de se esperar por um impune procedimento regularizatório. A possibilidade de flexibilização de requisitos urbanísticos a fim de que o solo urbano passe a ser considerado regular deverá surgir em um âmbito específico do bojo da regularização fundiária, jamais isentando empreendedores imobiliários de cumprirem as obrigações estabelecidas na Lei número 6.766/79, as quais permanecem válidas e vigentes, e passíveis de fiscalização pelos agentes jurídicos do tecido urbano.

Conquanto seja altamente questionável o modelo de criminalização adotado pela Lei 6.766 , os principais agentes fiscalizadores da concretização do direito fundamental à moradia por meio de parcelamentos são o Município e o Ministério Público, os quais devem permanentemente zelar para que os loteadores cumpram com suas obrigações de aprimoramento do solo urbano. A possibilidade de flexibilização de requisitos de um lote urbano não deve ser vista como uma prescrição do direito de exigir do loteador o 
cumprimento da lei, na forma do artigo 14 da Lei 13.465, segundo o qual "o requerimento de instauração da Reurb por proprietários de terreno, loteadores e incorporadores que tenham dado causa à formação de núcleos urbanos informais, ou os seus sucessores, não os eximirá de responsabilidades administrativa, civil ou criminal". Esta conjectura, entretanto, é plenamente compatível com o transporte de moradias irregulares para a legalidade, de maneira posterior e com vistas a não tornar desprotegida ou excluída do Direito uma situação de fato consolidada com o decorrer tempo.

\section{BIBLIOGRAFIA}

CARVALHO FILHO, José dos Santos. Comentários ao estatuto da cidade. 5 ed. ver. ampl. e atual. São Paulo: Atlas, 2013.

FARIAS, Cristiano Chaves de e ROSENVALD, Nelson. Curso de Direito Civil Vol. 5 direitos reais. 10 ed. rev. atual. e ampl. Salvador: Juspodivm, 2014.

LEAL, Rogério Gesta. Estado, administração pública e sociedade novos paradigmas. Porto Alegre: Livraria do advogado, 2006.

LEFEBVRE, Henri. O direito à cidade. São Paulo: Centauro, 2011.

NALINI, José Renato; LEVY, Wilson. Regularização fundiária. 2. ed. rev. atual. e ampl. Rio de Janeiro: Forense, 2014.

SARLET, Ingo Wolfgang. A eficácia dos direitos fundamentais: uma teoria geral dos direitos fundamentais na perspectiva constitucional. 12 ed. rev. atual. e ampl. Porto Alegre: Livraria do Advogado, 2015.

SARLET, Ingo Wolfgang. Comentário ao artigo $6^{\circ}$. In: CANOTILHO, J. J. Gomes; MENDES, Gilmar F.; STRECK, Lênio L.; ___ (Coords.). Comentários à Constituição do Brasil. São Paulo: Saraiva/Almedina, 2013.

SILVA, José Afonso da. Curso de Direito Constitucional Positivo. 6 ed. rev. e atual. São Paulo: Malheiros Editores, 2013. 
SOTO, Hernando de. The mystery of capital: why capitalism triumphs in the West and fails everywhere eles. New York: Basic Books, 2000.

Data de recebimento: 27.04 .2020

Data de aprovação: 12.06.2020 